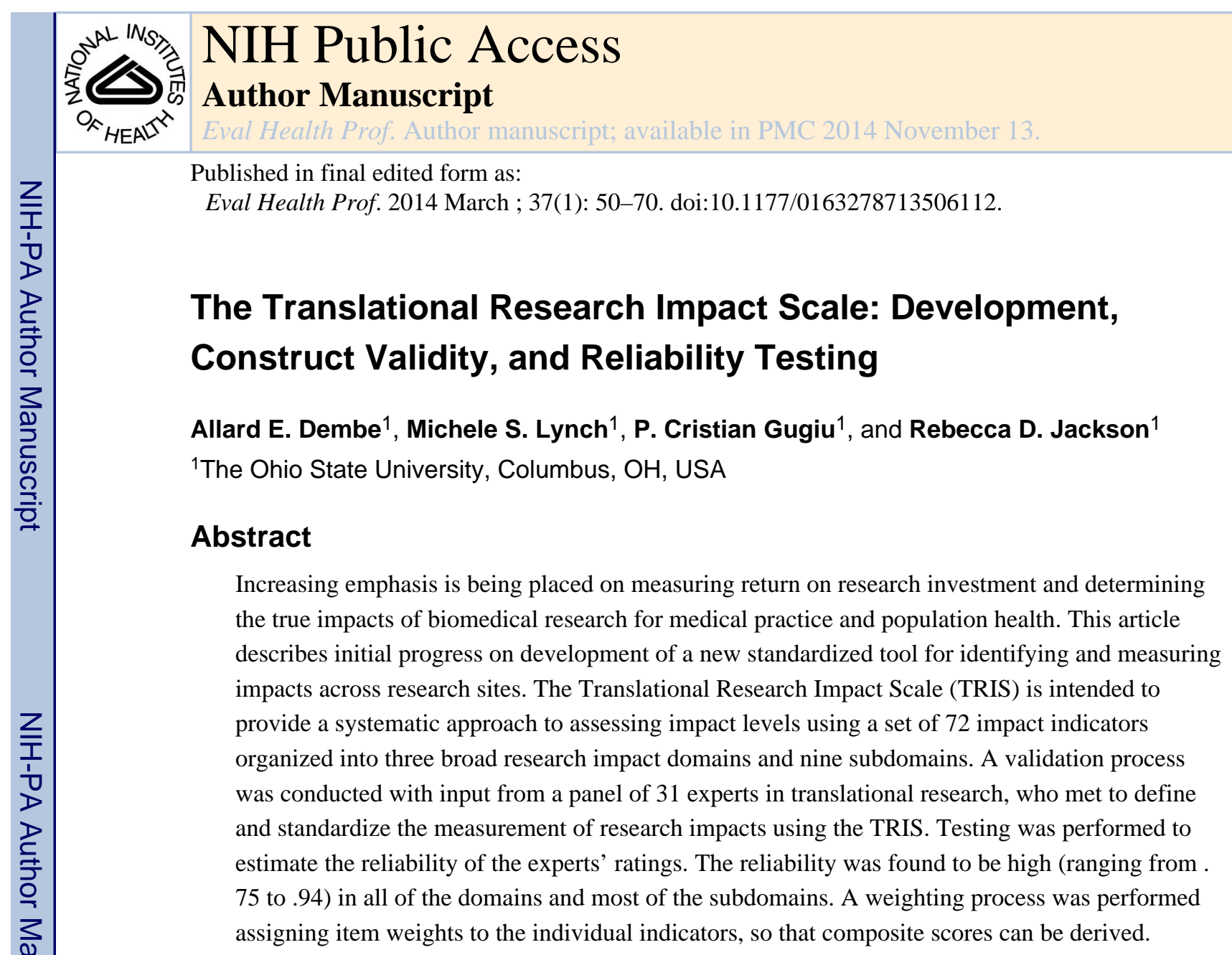

Keywords

translational research; impact; measurement; validity; reliability; CTSA

\title{
Introduction
}

How can the true impact of biomedical research best be assessed? Investigators and research institutions often assess impact by looking at easily determinable measures, such as the publication of articles in peer-reviewed journals, the impact factors of those journals, success in acquiring research grants, and the awarding of patents for novel inventions. In translational research, the ability to move drug discovery and basic research findings into animal or human trials might be considered a significant impact in a field. Similarly, the adoption of trial results into general medical practice might be considered a significant impact resulting from the research performed.

However, there are currently no standardized or systematic measurement techniques available for gauging the overall impact of biomedical and translational research. Many

(C) The Author(s) 2013

Corresponding Author: Allard E. Dembe, The Ohio State University, 1841 Neil Avenue, 283 Cunz Hall, Columbus, OH 43209, USA., adembe@cph.osu.edu.

Declaration of Conflicting Interests

The author(s) declared no potential conflicts of interest with respect to the research, authorship, and/or publication of this article. 
traditional measures of research impact, such as publication rates, impact factors, and patent awards, are relatively narrow in scope, and do not adequately measure the intermediate or long-term outcomes of the research enterprise, such as adoption of new diagnostic or therapeutic practices, changes in public policy, or improvements in population health.

The need to determine the true value of research has become more acute as government and private research institutes strive to justify expenditures and document tangible outcomes from research programs. The director of the National Institutes of Health (NIH) has estimated that NIH-sponsored biomedical research produces a two to one economic return on research investment (Collins, 2012). The recent establishment of NIH's “Impact of Research" website underscores the importance that agency attaches to measuring the ultimate benefits of biomedical research. According to that website, NIH's US $\$ 4$ billion investment in the Human Genome Project has produced US\$796 billion in economic growth between 2000 and 2010 - a 141-fold return on investment (National Institutes of Health, 2012).

The need to develop uniform methods for measuring research impact has taken on additional importance as the result of NIH's establishment of the Clinical and Translational Science Award (CTSA) program in 2006. Part of the rationale behind development of the CTSA program was to better understand and measure the contributions of translational research at academic research institutions. Various definitions of "translational research" have been proposed encompassing the continuum from translating basic science discovery derived from the bench all the way to translating findings to the community and modifying public policy. Some taxonomies classify the range of translational research into a four-phase model (T1 to T4; e.g., Khoury et al., 2007) while others adopt a two-phase (T1 to T2; e.g., Sung et al., 2003) or three-phase (T1 to T3) classification scheme (e.g., Dougherty \& Conway, 2008; Westfall, Mold, \& Fagnan, 2007). According to a three-phase framework developed by members of the Association for Clinical Research Training, translational research comprises three components including $\mathrm{T} 1$ research that expedites the movement from basic research and patient-oriented research to new scientific understanding and standards of care; T2 research that facilitates the movement from patient-oriented research and population-based research to better patient outcomes, implementation of best practices, and improved health status in communities; and T3 research promoting interaction between laboratory-based research and population-based research to stimulate scientific understanding of human health and disease (Rubio et al., 2010).

From the inception of the CTSA program, NIH has emphasized the need to systematically evaluate the extent to which these efforts are resulting in demonstrable benefits for individuals and communities. Indeed, NIH requires all CTSA programs to establish a process to measure program outcomes and document accomplishments.

Despite these ongoing efforts to assess the short- and long-term consequences of translational research, there are obstacles impeding such programs from comprehensively assessing their impacts. Glasgow (2009) has identified a variety of barriers in assessing the impacts from translational research programs, for example, the complexity of considering multilevel effects spanning diverse research settings, and investigators from a variety of 
disciplines. Quinlan, Kane, and Trochim (2008) point to difficulties in measuring translational research outcomes related to the need of collecting data from diverse sources in formats that may be incompatible to one another.

Moreover, there are currently no consistent standards or uniform measurement protocols specifying exactly what outcomes or impacts ought to be measured. As a result, some research organizations might place comparatively greater emphasis on measuring overt indicators of work output, such as grant awards, publications, patents, and number of investigator trainees. Others might focus more strongly on process and efficiency measures such as the time needed to obtain institutional review board (IRB) approvals or to recruit and schedule clinical trial participants. Likewise, some research sites may consider it important to evaluate structural factors, such as the ability to form interdisciplinary translational research project teams or increased communications between research units. Ultimately, research sponsors will want to see that the investment in translational research programs helps to achieve the longer term goals of improving medical practice and population health.

This article describes the Translational Research Impact Scale (TRIS), which is designed to provide a standardized measurement tool that will provide a practical, objective identification and measurement of the overall impact of translational research activities conducted in a research environment. It is intended to be used to measure the diversity of short- and long-term impacts that result from translational research activities. The ultimate goal underlying TRIS development is the potential for greater capacity to identify and document significant achievements at institutions conducting translational research, along with the ability to uniformly measure trends over time and potentially across research sites using a standardized impact assessment scale. This report describes the initial development and conceptual framework of the TRIS, a construct validation process for the TRIS undertaken by an expert panel that involved collecting evidence for validity based on test content, and reliability testing of the resulting measurement scale.

\section{Conceptual Model}

TRIS derives from a logic model originally developed by the W. K. Kellogg Foundation (2004a, 2004b). The basic framework for logic models developed by the Kellogg Foundation has been utilized in a variety of contexts including health care, educational programs, international aid, energy development, and scientific research. Several studies have applied logic models to clinical and biomedical research (Hayes, Parchman, \& Howard, 2011; Kagan, Kane, Quinlan, Rosas, \& Trochim, 2009; Sanders, Robinson, Forster, Plax, \& Brosco, 2005).

Common to these logic models is the assumption of a relationship between program inputs and activities and subsequent outputs and tangible outcomes, including short-term, intermediate, and long-term impacts. Applying the Kellogg Foundation's basic model to the translational research enterprise, inputs potentially include such things as laboratories, investigators, information systems, cell lines, funding, and other basic resources required for translational research. According to the model, program activities encompass the planning and conducting of translational research studies, animal and human preclinical investigations, the recruitment and training of investigators, IRB submissions, and other 
functions related to translational research. Outputs are the direct results of those activities, such as the number of translational science training programs held, genomic assays run, the quantity of clinical trial subjects recruited, the number of grant submissions made, or the number of relevant articles published. Outcomes include the specific changes that have occurred in processes, knowledge, treatments, methods, techniques, medical practice, or other indicators of tangible changes made, related to achieving the goals of translational research. Under this organizational scheme, impacts are the ultimate effects (e.g., on society, communities, patients, providers, etc.) resulting from the translational research process. Contextual factors can also be considered in the logic mode, such as ambient macroeconomic conditions, NIH policies, national health care reform legislation, and so on.

Some short-term outcomes (e.g., improvements in the research process) may occur relatively quickly (e.g., immediately or within a couple years), while others might take several years (e.g., 2-5 years) to achieve. Long-term outcomes (e.g., changes in medical practice, guideline development, and drug approval) might take 5-10 years or more. Demonstrable impacts on individuals and communities brought about by translational research (such as improved health status, disease rates, health care cost improvements) might not be manifest until a considerable time passes.

A diagram portraying a simplified logic model containing examples of relevant components that may be particularly germane to identifying and measuring the impacts achieved through translational research programs can be accessed at http://cph.osu.edu/sites/default/files/docs/ TRIS_Logic_Model.pdf

\section{Method}

\section{Literature Review}

A systematic review of existing research literature was conducted to help identify indicators of translational research impact. Google Scholar and PubMed databases were searched using the following terms: translational research, clinical and translational research, biomedical, measure, measurement, outcome, impact, research impact, and interdisciplinary. Articles were restricted to those published between January 1, 1998, and December 31, 2012, to help ensure relevancy to the contemporary understanding of translational research. We excluded articles that assessed research impact solely on the basis of bibliographic considerations, for example, the impact factor of published research articles (e.g., Rosas, Kagan, Schouten, Slack, \& Trochim, 2011; Sypsa \& Hatzakis, 2009).

Nearly 100 articles matched one or more of these criteria. Two investigators reviewed each article and compiled a subset of 26 articles that were appraised as focusing most directly on the measurement of research impact in the biomedical and translational sciences. A listing of these articles is provided in Table 1. Some of the articles involved empirical studies estimating research impact (e.g., RAND Europe, 2006), while other articles described general approaches and conceptual models relevant to the topic (e.g., Weiss, 2007). Among those 26 articles, 79 potential indicators and measures of research impact were reported. 
Each potential indicator was categorized into one of the three broad research impact domains (research-related impacts, translational impacts, and societal impacts) divided into nine more specific subdomains (Table 2). Identification of these domains and subdomains was influenced heavily by the health research impact framework developed by Kuruvilla, Mays, Pleasant, and Walt (2006) and similar efforts from the Becker Library at Washington University (Sarli, Dubinsky, \& Holmes, 2010).

\section{Validation Process}

An initial set of 79 potential research impact indicators was identified through the systematic literature review, as described above. The aim of the expert panel process was to help confirm the selection of the indicator set as appropriate markers of translational research impact. A solicitation for participation in an expert panel was sent to 72 senior researchers in the field of clinical and translational research, representing a variety of perspectives along the scientific translational continuum from T1 to T4 research. All panel members were associated with one research university that is funded by a CTSA from NIH. Thirty-one investigators agreed to participate in the validation process. Information regarding the characteristics of the expert panel members can be accessed at http://cph.osu.edu/sites/ default/files/docs/TRIS_Expert_Panel_Members.pdf

Several group meetings were held, at which the panel members were presented with each of the 79 indicators and asked to assess the extent to which they agreed that each indicator appropriately measured the target construct (i.e., the impact of translational research). Panelists were instructed to provide their answers independently from one another. Responses were recorded using a 5-point ordinal scale (strongly agree, agree, neutral, disagree, strongly disagree, with $1=$ strongly agree and $5=$ strongly disagree). A statistical summary of the means and standard deviations of the panel members' responses was compiled. We established a decision criterion under which at least a majority (more than $50 \%$ ) of the expert panel participants must have responded either strongly agreed or agreed in order for that indicator to be retained in the final indicator set.

Additionally, in order to determine item weights, each panel member was asked to compare the importance of a particular item relative to others, also on a 5-point ordinal scale (much more important than others, more important than others, equally important as others, less important than others, and not important, with $1=$ much more important than others and $5=$ not important). Item weights were only determined for the indicators that met the indicator retention criterion specified above. The weighting value given to each indicator was determined by calculating how far the mean for a particular indicator deviated from the mean for all indicators aggregated on the weighting scale. So, for example, if the mean of a particular indicator was 2.2 and the aggregated mean weighting for all indicators was 2.5 , then the weight assigned to that indicator was $[(2.5-2.2) / 2.5]+1=1.12$.

\section{Reliability Determination}

The reliability of these responses were estimated using a variety of approaches, including calculation of the coefficient a (Cronbach, 1951), Ordinal a and $\omega$ (Gugiu, Coryn, \& Applegate, 2010; Zumbo, Gadermann, \& Zeisser, 2007), and the nonparametric bootstrap 
split-half reliability (Gugiu, 2011) techniques. Reliability estimations were performed for both the initial construct validation process and for the item weighting process. Several reliability estimation techniques were employed to ensure that results were generally consistent across testing methods. Ordinal a and ordinal $\omega$ tests are appropriate in this context, owing to our use of ordinal scales. However, those methods assume that bivariate normality exists between each pair of items. Since testing this assumption is not easy and requires further assumptions, a nonparametric reliability estimator (the bootstrap/Spearman test) was employed along with Cronbach's a (typically used for continuous data) as additional comparisons. Findings among the various techniques were quite similar. The reliability calculations were performed using SAS statistical software, version 9.3.

\section{Results}

Overall, the average rating per indicator was 1.98 on the ordinal scale (with 1.0 being the strongest level of agreement). Of the 79 proposed indicators, 7 (\#4, 11, 41, 61, 62, 65, and 71) of the indicators failed to meet the inclusion criterion, and were thus dropped from further consideration as a suitable indicator of translational research impact. The average item weighting value among indicators was 2.59 on the 5-point ordinal scale comparing perceived differences in importance among items.

For both the construct validation and item weighting processes, the degree of reliability for expert panel agreement was generally high, with estimates within the three domains ranging from .87 (based on the Bootstrap/Spearman test) to .94 (based on the Cronbach's $\omega$ test) for the construct validation process (Table 3 ), and ranging between .88 (based on the Cronbach's a test) and .96 (based on the Ordinal $\omega$ test) for the item weighting process domains (Table 4). Estimates of reliability for the degree of expert panel agreement in the nine subdomains for the construct validation process all exceeded .66 (based on the Bootstrap/Spearman test), and were greater than .75 in five of those subdomains. Similar results were observed in the reliability estimates of expert panel agreement for the item weighting process, with estimates greater than .71 in all subdomains except the Research Direction and Resources subdomain, which had reliability estimates ranging from .52 to .63 , depending on the test used.

\section{Discussion}

This study represents perhaps the first attempt to create a uniform standardized scale for measuring the impacts of translational research. As pressure mounts to justify and document research expenditures, it becomes increasingly important to use validated and customized metrics that capture the distinctive features of translational research. TRIS potentially allows for benchmarking and comparison of impacts among research institutions.

Concentrating on the development of weighted scales based on a uniform set of indicators provides a specific measurement approach that has been lacking in other attempts to measure and quantify translational research impacts. At this writing, the closest movement so far in this direction was the April 2012 CTSA National Evaluation Report prepared by Westat Inc. for NIH (Frechtling, Raue, Michie, Miyaoka, \& Spiegelman, 2012). That 
evaluation process used an assortment of inputs including surveys of investigators, analysis of publications data, reviews of site annual reports, and field visits to provide an overall assessment of progress by CTSA programs. The evaluation reported on quantifiable indicators of CTSA site processes and results. It did not include any aggregate measure or score of CTSA performance. Importantly, the goal and orientation of that project is conceptually distinct from our attempt to create a scale by which to measure the ultimate impacts of translational research. While some of the domains are common to both projects (e.g., publications, grants, extent of collaboration, use of research resources), our development of the TRIS focuses directly on the need to score the attainment of impact in various areas to calculate domain and composite scores that can be used as a basis for comparing performance and ultimate impact of research efforts across research sites.

Our development of TRIS was motivated primarily by a desire to develop a uniform method for accessing translational research impacts across CTSA sites. However, we attempted to structure the measurement tool in a way that potentially could be adopted within many kinds of research organizations, including commercial biomedical research facilities, academic institutions without CTSA programs, and other appropriate settings.

Our development of TRIS and the associated construct validity and reliability testing processes we performed were based on a methodical analytical process consisting of systematic literature review and expert panel rating to help develop and refine the measurement tool. By contrast, the Westat report was broadly based but not designed to produce a particular set of quantified research impact indicators. That report does not specify the basis for selecting particular evaluation items, how many or what specific types of evaluation metrics were used, or how the separate results obtained from the evaluation process could be combined into a synthetic whole that could be used for comparisons and benchmarking among sites.

\section{Challenges, Limitation, Future Research}

This study focuses on the initial development of TRIS, the selection of appropriate indicators for denoting construct validity, reliability assessment, and item weighting. These achievements represent the initial progress that has been made toward the larger goal of actually putting the TRIS into practice. However, more work is needed to reach that goal. Next steps will include further testing of the tool's psychometric properties and the beginning of field testing. Field testing will be important in determining the ability to use available data to measure levels of attainment for each impact indicator. Also, the appropriate time frames for measuring impact need to be determined. For example, some impacts might be measurable in a relatively brief period of time (e.g., 1 or 2 years), while others might require a longer time frame to measure true impact in a particular area. To facilitate the generalizability of the measurements, it will be necessary to extend field testing and operationalizing of the TRIS scale across research sites that differ in their relative focus on $\mathrm{T} 1$ to $\mathrm{T} 4$ research activities.

Additionally, the measurement process for each particular indicator will need to be operationalized to yield a measure of impact attainment. One way of developing that system, for example, would involve assigning possible impact attainment criteria for each indicator 
to allow for classifying the existing level of impact attainment into one of the several values (e.g., on a Likert-type scale). Field studies will be helpful in determining the feasibility and cost of compiling those measurements. Unless the impacts can be measured and quantified easily, TRIS may fail to be used by research institutions. The next phase of this project that will develop the requisite measurement processes is expected to be completed by the end of 2014. Other CTSA sites have been approached about the possibility of collaborating in data collection and field testing of the instrument.

Our eventual goal is to develop an aggregate composite score for measuring research impact attainment across sites. In subsequent studies, we intend to explore the internal validity of the instrument. Due to the low sample size in the current study, factor analysis was not a viable option for this pilot study. Once TRIS' internal validity and reliability have been satisfactorily addressed, we will then investigate its criterion validity, using empirical data of impact attainment at various sites.

Based on our inclusion criteria and the ratings of the expert panelists, 7 of the 79 indicators originally identified $(\# 4,11,41,61,62,65$, and 71) were dropped from the final indicator set. Four of the deleted group focused on policy development and societal impacts, which may have been perceived by some panelists as less discrete or measurable for assessing research impact. The item (\#4) regarding clarifying the terminology used to describe the T1T4 translational spectrum also was dropped, perhaps indicating some continuing confusion about that concept among researchers.

We believe that developing and testing a uniform process for measuring translational research impact is essential to the success of the CTSA program and, ultimately, to the broader translational research enterprise in the U.S. NIH and other sponsors of research need to see demonstrable results from research expenditures and tangible improvements in population and community health. TRIS is being developed as a standardized instrument to provide uniform impact metrics that allow for comparing results across sites and documenting accomplishments in a consistent way. Our progress to date sets the foundation for further refinement of the tool and field testing with empirical data to establish criterion validity and measurement feasibility.

\section{Acknowledgments}

\section{Funding}

The author(s) disclosed receipt of the following financial support for the research, authorship, and/or publication of this article: This project described was supported by Award Number 8UL1TR000090 from the National Center For Advancing Translational Sciences. The content is solely the responsibility of the authors and does not necessarily represent the official views of the National Center For Advancing Translational Sciences or the National Institutes of Health.

\section{References}

Aries N, Sclar E. The economic impact of biomedical research: A case study of voluntary institutions in the New York metropolitan region. Journal of Health Politics, Policy and Law. 1998; 23:175193.

Australian Research Council. Excellence in research for Australia (ERA) initiative. Canberra, Australia: Author; 2008. Retrieved from http://www.arc.gov.au/pdf/ERA_ConsultationPaper.pdf 
Collins, FS. Protecting the future of U.S. biomedical research. 2012. Retrieved December 7, 2012, from http://www.nih.gov/about/director/12072012_state-ment_biomedicalresearch.htm

Cronbach LJ. Coefficient alpha and the internal structure of tests. Psychometrika. 1951; 16:297-334.

Donaldson NE, Rutledge DN, Ashley J. Outcomes of adoption: Measuring evidence uptake by individuals and organizations. Worldviews on Evidence-Based Nursing. 2004; S1:S41-S51. [PubMed: 17129334]

Dougherty D, Conway P. The "3T's" road map to transform U.S. health care: The "how" of highquality care. Journal of American Medical Association. 2008; 299:2319-2321.

Frechtling, J.; Raue, K.; Michie, J.; Miyaoka, A.; Spiegelman, M. The CTSA national evaluation final report. 2012. Retrieved April 3, 2012, from https://www.ctsacen-tral.org/sites/default/files/files/ CTSANationalEval_FinalReport_20120416.pdf

Glasgow RE. Critical measurement issues in translational research. Research on Social Work Practice. 2009; 19:560-568.

Grant J, Cottrell R, Cluzeau F, Fawcett G. Evaluating 'payback' on biomedical research from papers cited in clinical guidelines: Applied biblio-metric study. British Medical Journal. 2000; 320:11071111. [PubMed: 10775218]

Gugiu, PC. Summative confidence (Unpublished doctoral dissertation). Kalamazoo, MI: Western Michigan University; 2011.

Gugiu PC, Coryn CLS, Applegate EB. Structure and measurement properties of the patient assessment of chronic illness care (PACIC) instrument. Journal of Evaluation in Clinical Practice. 2010; 16:509-516. [PubMed: 20210824]

Hanney SR, Grant J, Wooding S, Buxton MJ. Proposed methods for reviewing the outcomes of health research: The impact of funding by the UK's 'Arthritis Research Campaign.'. Health Research Policy and Systems. 2004; 2:4. [PubMed: 15272939]

Hayes H, Parchman ML, Howard RA. Logic model framework for evaluation and planning in a primary care practice-based research network (PBRN). Journal of the American Board of Family Medicine. 2011; 24:576-582. [PubMed: 21900441]

Haynes B, Haines A. Barriers and bridges to evidence based clinical practice. British Medical Journal. 1998; 317:273-276. [PubMed: 9677226]

Heller C, de Melo-Martin I. Clinical and translational science awards: Can they increase the efficiency and speed of clinical and translational research? Academic Medicine. 2009; 84:424-432. [PubMed: 19318771]

Kagan JM, Kane M, Quinlan KM, Rosas S, Trochim WM. Developing a conceptual framework for an evaluation system for the NIAID HPV/AIDS clinical trials networks. Health Research Policy and Systems. 2009; 7:1-16. [PubMed: 19121210]

Kalucy L, Mclntyre E, Jackson-Bowers E, Reed R. Exploring the impact of primary health care research projects using the Payback Framework. Health Research Policy and Systems. 2009; 7:11. [PubMed: 19422717]

Kessler R, Glasgow RE. A proposal to speed translation of healthcare research into practice; dramatic change is needed. American Journal of Preventive Medicine. 2011; 40:637-644. [PubMed: 21565657]

Khoury ML, Gwinn M, Yoon PW, Dowling N, Moore CA, Bradley L. The continuum of translation research in genomic medicine: How can we accelerate the appropriate integration of human genome discoveries into health care and disease prevention? Genetics in Medicine. 2007; 9:665674. [PubMed: 18073579]

Kuruvilla S, Mays N, Pleasant A, Walt G. Describing the impact of health research: A research impact framework. BMC Health Services Research. 2006; 6:134. [PubMed: 17049092]

Lavis J, Ross S, McLeod C, Gildiner A. Measuring the impact of health research. Journal of Health Services Research \& Policy. 2003; 8:165-170. [PubMed: 12869343]

Lewison G. Beyond outputs: New measures of biomedical research impact. Aslib Proceedings: New Information Perspectives. 2003; 55:32-42.

Mankoff S, Brander C, Ferrone S, Marincola F. Commentary: Lost in translation: Obstacles to translational medicine. Journal of Translational Medicine. 2004; 2:14. [PubMed: 15149545] 
Nathan D. Commentary: Careers in translational clinical research-Historical perspectives, future challenges. The Journal of the American Medical Association. 2002; 287:2424-2427.

National Institutes of Health. Our economy. 2012. Retrieved from http://www.nih.gov/about/impact/ economy.htm

Pang T, Sadana R, Hanney S, Bhutta Z, Hyder A, Simon J. Knowledge for better health-A conceptual framework and foundation for health research systems. Bulletin of the World Health Organization. 2003; 81:815-820. [PubMed: 14758408]

Pober JS, Neuhauser CS, Pober JM. Obstacles facing translational research in academic medical centers. The Federation of American Societies for Experimental Biology (FASEB) Journal. 2001; 15:2303-2313.

Quinlan KM, Kane M, Trochim WM. Evaluation of large research initiatives: Outcomes, challenges, and methodological considerations. New Directions for Evaluation. 2008; 118:61-72.

RAND Europe. Measuring the benefits from research. Cambridge, England: Author; 2006. Retrieved from http://www.rand.org/Pubs/researchbriefs/2007/RAND-RB9202.pdf

Rosas SR, Kagan JM, Schouten JT, Slack PA, Trochim WMK. Evaluating research and impact: A bibliometric analysis of research by the NIH/NIAID HIV/AIDS clinical trials networks. PLoS ONE. 2011; 6:e17428. [PubMed: 21394198]

Rubio DG, Schoenbaum EE, Lee LS, Schteingart DE, Marantz PR, Anderson KE, Esposito K. Defining translational research: Implications for training. Academic Medicine. 2010; 85:470-475. [PubMed: 20182120]

Sanders LM, Robinson TN, Forster LQ, Plax K, Brosco JP. Evidence-based community pediatrics: Building a bridge from bedside to neighborhood. Pediatrics. 2005; 115:1142-1147. [PubMed: 15821298]

Sarli C, Dubinsky EK, Holmes K. Beyond citation analysis: A model for assessment of research impact. Journal of the Medical Library Association. 2010; 98:17-23. [PubMed: 20098647]

Sypsa V, Hatzakis A. Assessing the impact of biomedical research in academic institutions of disparate sizes. BMC Medical Research Methodology. 2009; 9:33. [PubMed: 19480665]

Sung NS, Crowley WF, Genel M, Salber P, Sandy L, Sherwood LM, Rimoin D. Central challenges facing the national clinical research enterprise. The Journal of the American Medical Association. 2003; 289:1278-1287.

Trochim W, Kane C, Graham M, Pincus H. Evaluating translational research: A process marker model. Clinical and Translational Science. 2011; 4:153-162. [PubMed: 21707944]

Trochim WM, Marcus SE, Masse LC, Moser RP, Weld PC. The evaluation of large research initiatives: A participatory integrative mixed-methods approach. American Journal of Evaluation. 2008; 29:8-28.

Weiss A. Measuring the impact of medical research: Moving from outputs to outcomes. American Journal of Psychiatry. 2007; 164:206-214. [PubMed: 17267781]

Westfall J, Mold J, Fagnan L. Practice-based research_'Blue highways' on the NIH roadmap. The Journal of the American Medical Association. 2007; 297:403-406.

W. K. Kellogg Foundation. Logic model development guide. Battle Creek, MI: Author; 2004a.

W. K. Kellogg Foundation. Evaluation handbook. Battle Creek, MI: Author; 2004b.

Woolf S. The meaning of translational research and why it matters. The Journal of the American Medical Association. 2008; 299:211-213.

Zerhouni EA. Translational research: Moving discovery to practice. Clinical Pharmacology \& Therapeutics. 2007; 81:126-128. [PubMed: 17186011]

Zumbo BD, Gaderman A, Zeisser C. Ordinal versions of coefficients alpha and theta for Likert rating scales. Journal of Modern Applied Statistical Methods. 2007; 6:21-29. 


\section{Table 1}

Articles Mentioning Potential Translational Research Impact Indicators.

\begin{tabular}{ll}
\hline Article citation & Indicator numbers \\
\hline 1. Aries and Sclar (1998) & 70,71 \\
2. Australian Research Council (2008) & $27,31,32,36,37,38$ \\
3. Donaldson, Rutledge, and Ashley (2004) & $48,54,55$ \\
4. Dougherty and Conway (2008) & $25,46,54,55,57,60,69$ \\
5. Grant, Cottrell, Cluzeau, and Fawcett (2000) & 57,54 \\
6. Hanney, Grant, Wooding, and Buxton (2004) & $5,29,38,49,52,57,70$ \\
7. Haynes and Haines (1998) & $50,57,67$ \\
8. Heller and de Melo-Martin (2009) & $1,2,5,6,7,11,13,16,18,19,47,73,74$ \\
9. Kalucy, Mclntyre, Jackson-Bowers, and Reed (2009) & $29,31,37,40,42,67,70$ \\
10. Kessler and Glasgow (2011) & $18,21,22,60$ \\
11. Kuruvilla, Mays, Pleasant, and Walt (2006) & $1,3,5,11,14,15,17,21,23,24,32,34,35,38$, \\
& $39,40,41,42,47,50,51,52,54,56,57,63$, \\
12. Lavis, Ross, McLeod, and Gildiner (2003) & $26,27,28,29,30,31,32,33,34$ \\
13. Lewison (2003) & $26,32,35,37,39,40,44,52,55,56,57,62$ \\
14. Mankoff, Brander, Ferrone, and Marincola (2004) & $4,16,18,28,31,47,49,52,58$ \\
15. Nathan (2002) & 11,12 \\
16. Pang et al. (2003) & $24,31,35,40,47,57,67,68$ \\
17. Pober, Neuhauser, and Pober (2001) & $8,9,12,13,14,18,19,43,47,49,52,78$ \\
18. RAND Europe (2006) & $36,38,70$ \\
19. Sarli, Dubinsky, and Holmes (2010) & Extensive list (>40 indicators): \\
20. Sung et al. (2003) & $2,7,8,13,17,18,49,52$ \\
21. Trochim, Kane, Graham, and Pincus(2011) & $29,30,47,57$ \\
22. Trochim, Marcus, Masse, Moser, and Weld (2008) & $1,3,4,5,12,22,25,44$ \\
23. Weiss (2007) & $1,10,12,21,22,27,35,36,38,40,42,47,55$, \\
& $61,63,69,70,76,77,78$ \\
24. Westfall, Mold, and Fagnan (2007) & $20,47,54$ \\
25. Woolf (2008) & $30,34,43,44,45,56,59,72,74$ \\
26. Zerhouni (2007) & $33,43,58,73$ \\
\hline & \\
\hline
\end{tabular}


Table 2

Translational Research Impact Scale: Domains, Subdomains, and Impact Indicator.

\begin{tabular}{|c|c|}
\hline $\begin{array}{l}\text { Impact } \\
\text { indicator } \\
\text { number }\end{array}$ & Brief description of impact indicator \\
\hline \multicolumn{2}{|c|}{ Domain 1. Research-related impacts } \\
\hline \multicolumn{2}{|c|}{ Subdomain 1: research direction and resources (RDR) } \\
\hline RDR 1 & $\begin{array}{l}\text { Research needs are identified, such as gaps in research, } \\
\text { unanswered questions, or identification of new areas for } \\
\text { investigation }\end{array}$ \\
\hline RDR 2 & $\begin{array}{l}\text { New methods are developed for collecting and storing data; and/ } \\
\text { or building new database systems }\end{array}$ \\
\hline RDR 3 & New research methods or techniques are developed or extended \\
\hline $\mathrm{RDR} 4^{a}$ & $\begin{array}{l}\text { Translational research concepts, definitions, and terminology are } \\
\text { better defined or elucidated (e.g., the nomenclature of TI-T4 } \\
\text { to describe phases of translational research) }\end{array}$ \\
\hline RDR 5 & Effective new research networks and collaborations are formed \\
\hline RDR 6 & Qualified research personnel are recruited \\
\hline \multicolumn{2}{|c|}{ Subdomain 2: research management and conduct (RMC) } \\
\hline RMC 7 & $\begin{array}{l}\text { Improved methods for recruitment of study participants are } \\
\text { developed and/or implemented }\end{array}$ \\
\hline RMC 8 & $\begin{array}{l}\text { IRB processes are improved (e.g., shortening the time to } \\
\text { approval, ease of completion, and appropriateness of decisions) }\end{array}$ \\
\hline RMC 9 & New research projects and teams are formed \\
\hline RMC 10 & Translational research studies are successfully completed \\
\hline$(\mathrm{RMC} \mathrm{11})^{a}$ & $\begin{array}{l}\text { Improved retention and continuity of research team/teams is } \\
\text { achieved }\end{array}$ \\
\hline $\mathrm{RMC} 12$ & $\begin{array}{l}\text { Improvements in the quality or quantity of teamwork across } \\
\text { disciplines occur }\end{array}$ \\
\hline RMC 13 & Process efficiencies in the conduct of research are achieved \\
\hline RMC 14 & Researchers or staff are recognized for leadership in the field \\
\hline RMC 15 & $\begin{array}{l}\text { A particular translational study or the research unit receives an } \\
\text { award }\end{array}$ \\
\hline RMC 16 & $\begin{array}{l}\text { Internal communication among individual researchers and among } \\
\text { research units is improved }\end{array}$ \\
\hline $\mathrm{RMC} 17$ & $\begin{array}{l}\text { More of the unit's researchers and staff serve on regional or } \\
\text { national research organizations (e.g., NIH study sections) }\end{array}$ \\
\hline $\mathrm{RMC} 18$ & $\begin{array}{l}\text { Significant positive changes in the research environment and } \\
\text { culture occur }\end{array}$ \\
\hline RMC 19 & $\begin{array}{l}\text { Barriers in the research process are identified and strategies for } \\
\text { overcoming those barriers are developed }\end{array}$ \\
\hline RMC 20 & $\begin{array}{l}\text { There is an increased emphasis on conducting practice-based } \\
\text { research (in "real-world" clinical settings) }\end{array}$ \\
\hline \multicolumn{2}{|c|}{ Subdomain 3: research methods (RM) } \\
\hline RM 21 & New analytical techniques are developed \\
\hline RM 22 & New or improved mixed-methods approaches are used \\
\hline RM 23 & $\begin{array}{l}\text { New or improved methods for conducting studies spanning } \\
\text { multiple disciplines are established }\end{array}$ \\
\hline RM 24 & $\begin{array}{l}\text { New methods of synthesizing results from varying disciplines are } \\
\text { implemented }\end{array}$ \\
\hline
\end{tabular}




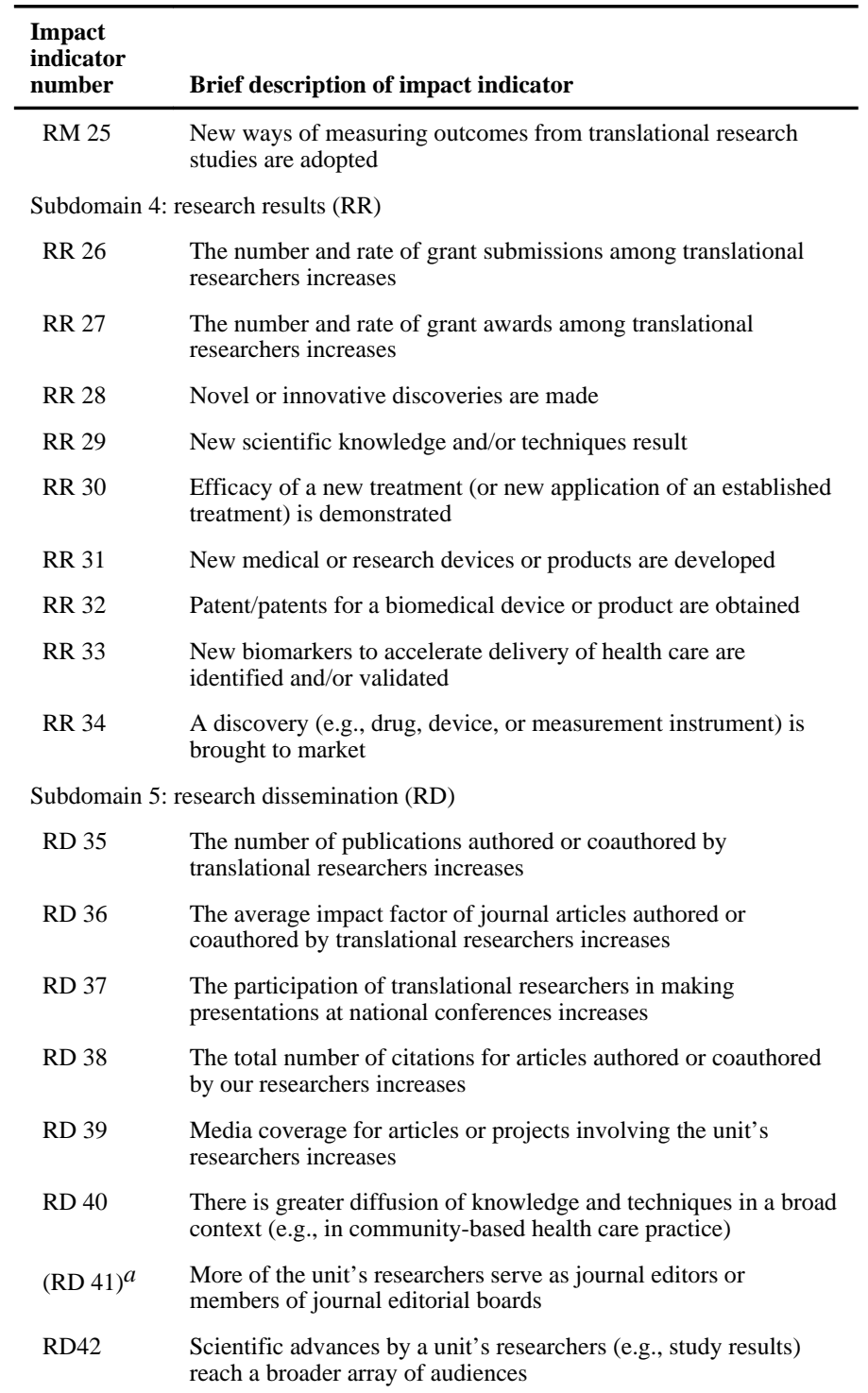

Domain 2. Translational impacts (TI)

Subdomain 6: translational impacts (TI)

TI 43 Findings and discoveries from bench science are incorporated into studies involving animals or humans

TI 44 Findings and discoveries from clinical trials are incorporated into clinical guidelines, or otherwise accepted as good medical practice

TI 45 Improvements in the delivery of effective and efficient health care services are made

TI 46 The effectiveness of different treatment and intervention choices are determined in a manner that is useful for clinicians

TI 47 Improvements result in better quality of patient care

TI 48 The incidence of medical errors decreases

TI 49 Increased training in translational research methods occurs among health care providers and support personnel 


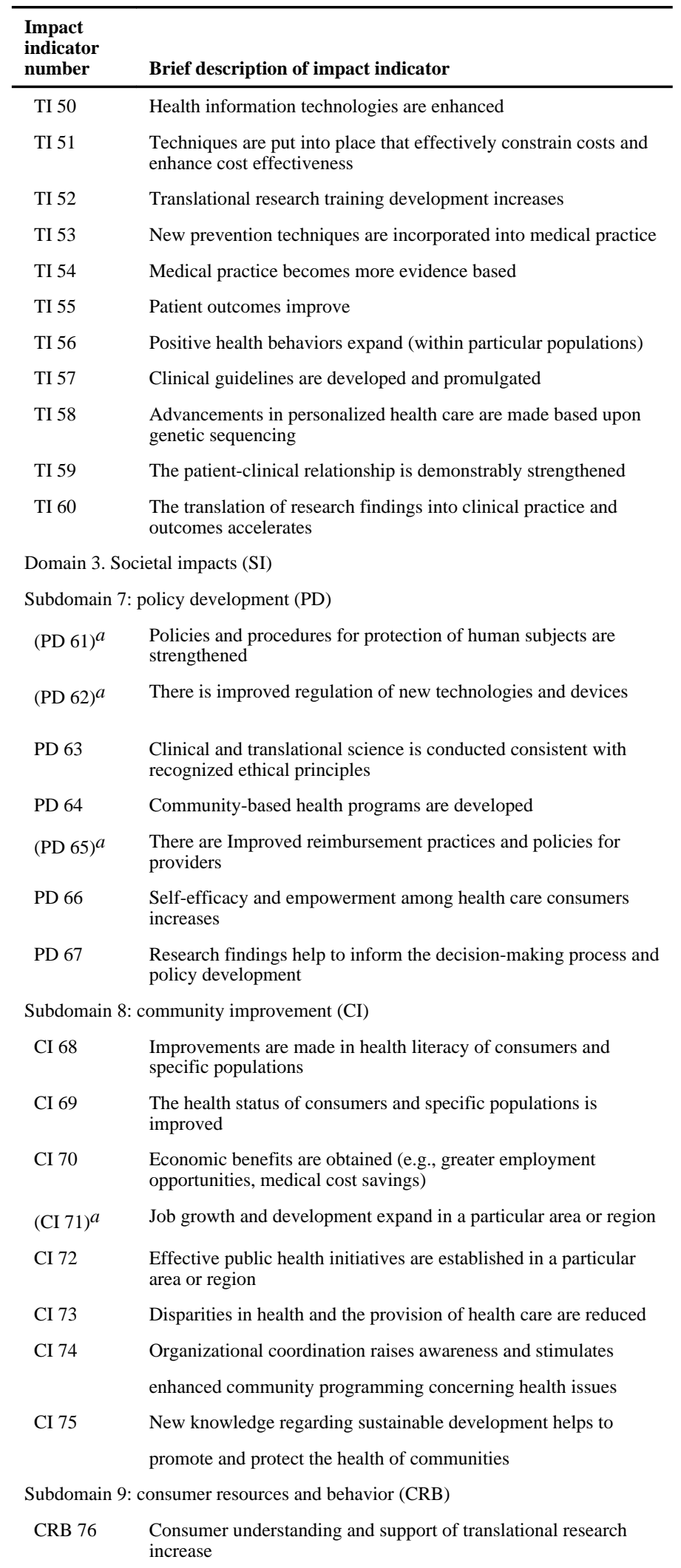




\begin{tabular}{ll}
\hline $\begin{array}{l}\text { Impact } \\
\text { indicator } \\
\text { number }\end{array}$ & Brief description of impact indicator \\
\hline CRB 77 & $\begin{array}{l}\text { Consumers feel more empowered about health issues and their } \\
\text { ability to affect change }\end{array}$ \\
CRB 78 & $\begin{array}{l}\text { There is improved communication and understanding about } \\
\text { health risks among consumers }\end{array}$ \\
CRB 79 & Health education and health literacy expands \\
\hline
\end{tabular}

Note. $\mathrm{IRB}=$ institutional review board; $\mathrm{NIH}=$ National Institutes of Health.

$a_{\text {Indicators not included in final indicator set. }}$ 
